\title{
Students' intention to participate in urban agriculture program in Malaysia
}

\begin{abstract}
Recently, urban agriculture has been promoted in Malaysia to guarantee sources of food for the nation by 2020. In line with the new food policy, Universiti Putra Malaysia is planning to form a group of long-term student volunteers to train urban residents in implementing urban agriculture. Considering that students' participation in the program has a significant impact on the marketing of urban agriculture, it is essential to identify students' intention to participate for such a university program. Data were collected from 438 undergraduate students from the faculty of agriculture using a structured questionnaire. Results indicated that majority of students are intent to participate in the program. In conclusion, the university students' intention to participate in urban agriculture is at a high level.
\end{abstract}

Keyword: University students; Urban agriculture; Participation; Future intention; Malaysia 